\title{
Human immune suppression is inducible by trichosan- thin via CD8 cell-mediated pathway
}

\author{
CHOU KUANGYeN ${ }^{1}$, DONGQING ZHANG, BAOHUA \\ XUE \\ Shanghai Institute of Immunology, Shanghai Second Med- \\ ical University, Shanghai 200025, China.
}

\begin{abstract}
Trichosanthin( Tk), a polypeptide with 249 amino acid residues isolated and purified from a Chinese medicinal herb, showed the capability of inducing abortion and was able to inhibit tumor growth and HIV replication. Owing to sequence homology of the peptide with a ribosomeinactivating protein, the downward activity of Tk was suggested to be related to its cytotoxic property. We report here, however, that Tk could exert potent inhibitory effects on human lymphoproliferative responses in vitro to allogeneic, mitogenic and soluble antigens with 50\% inhibition doses ranged between 0.05 and $0.5 \mu \mathrm{g} / \mathrm{m} 1$. The lowresponsiveness caused by $\mathrm{Tk}$ was not due to toxic cytolysis. Rather, evidences suggested that, in the dose range adopted, the Tk-induced inhibition was attributable, at least in part, to immune suppression, in view of (1) $\mathrm{Tk}$ was more effective in the early stage of alloreactivity; (2) Suppression also occurred if responder cells were pulsetreated with Tk rather than cocultured; (3) Irradiated Tk-pulsed cells were capable of inducing suppression in a Tk-free culture; (4) Suppression could also be transferred by the supernatants of Tk-pulsed cultured cells; (5) Tkinduced immune suppression was diminished by depletion of CD8+ cells from the culture, and, finally; (6) Adding $\mathrm{CD} 8+$ cells back to the culture could restore the suppres-
\end{abstract}

1. Correspondence:Dr Kuangyen Chou, Shanghai Institute of Immunology, Shanghai Second Medical University, 280 South Chongqing Road, Shanghai 200025, China 
Trichosanthin-induced human immune suppression

sion: Thus the possibility that Tk might function as a down-regulator by immunological mechanisms in human immune responses is discussed.

Key words: Human immune suppression, Trichosanthin, CD8 T cell.

\section{INTRODUCTION}

Root tubers of Trichosanthes kirilowii Maximovich (Cucurbitaceae family), from which trichosanthin (Tk) was isolated, was described for its medicinal properties as early as the 16th century by the great Chinese scholar Shi-Zhen Li in his famous book 'Ben-Cao-Gang-Mu' (Compendium of Materia Medica) [1]. For hundreds of years the herb has since been used in folk medicine in China for treatment of various diseases. It was not until 1970s that Tk was identified to be the active component of the herb and used clinically as an abortifacient[2]. Tk was purified to crystalline form in 1981[3] and its primary structure was soon elucidated[4]. Based on a sequence homology between $\mathrm{Tk}$ molecule and ricin $\mathrm{A}$ chain, a ribosome-inactivating protein(RIP)[5], Tk was further conjugated with monoclonal antibo dies as immunotoxin in order to explore the possibility for cancer immunotherapy[6,7]. Moreover, McGrath and his colleagues (1989) established that Tk (designated in their study as GLQ223) had potent inhibitory activity against human immunodeficiency virus (HIV) replication in vitro[8]. Since then several Tk preparations have been developed showing promise for AIDS treatment[8-10], and clinical trails had also been carried out $[11,12]$. The Tk gene was further cloned and sequenced in 1990[13]. But so far little is known regarding its effect on the human immune system, although some immunological investigations in mice with $\mathrm{Tk}$ have been reported $[14,15]$. Of immediate interest is whether the immunological mechanism exerted by Tk, if any, might play a certain role in the AIDS control.

In this communication, data are presented showing that, in addition to its RIP property, Tk exhibited immunosuppressive activity even in lower concentration and the suppression was mediated by $\mathrm{CD}^{+} \mathrm{T}$ cells. Our results are favorable for exploring the mechanisms by which Tk showed its down-regulatory effects on immune responses and in HIV diseases.

\section{MATERIALS AND METHODS}

\section{Blood samples}

Blood samples donated by adult healthy volunteers were used for seperating the peripheral blood mononuclear cells (PBMCs).

Reagent 
Tk was obtained as a crystalline preparation dissolved in water from the Shanghai Jingshan Pharmaceutical Factory and the Shanghai Institute of Organic Chemistry, Chinese Academy of Sciences. The stock solution was diluted with saline to $0.05-0.1 \mathrm{mg} / \mathrm{ml}$. The diluted Tk was sterilized through $0.2 \mu \mathrm{m}$ millipore filter and stored as aliquots at $-70{ }^{\circ} \mathrm{C}$.

Phytohemagglutinin ( PHA) and tetanus toxoid (TT) were obtained from Phamacia Fine Chemicals (Piscataway, NJ) and Lederle Laboratories (Peael River, NY), respectively. Dose-response curves (data not shown) indicated that the optimal dosages for inducing lymphoproliferation were $5 \mu \mathrm{g} / \mathrm{ml}$ for PHA and $0.1 \mathrm{Lf} / \mathrm{ml}$ for TT ( $\mathrm{Lf}=$ limit flocculation, an amount giving the most rapid flocculation with one standard unit of antitoxoid). For PHA stimulation, however, only results with sub-optimal dosages were presented, which were more sensitive to reveal the inhibitory activity of Tk.

\section{Cell culture}

PBMCs were isolated from heparinized blood by Ficoll-Hypaque gradient. Cells were cultured in round-bottomed 96-well microtiter plates in RPMI-1640 medium (Whittaker M A Bioproducts Inc, Walkersville, MD) supplemented with $100 \mathrm{U} / \mathrm{ml}$ penicilin, $100 \mu \mathrm{g} / \mathrm{ml}$ streptomycin, $2 \mathrm{mM}$ 1-glutamine, HEPES, and 7\% pooled human AB sera (PHS). The plates were incubated in a humidified atmosphere of $5 \% \mathrm{CO}_{2}$ at $37{ }^{\circ} \mathrm{C}$. Sixteen hours before termination of culturing, $1 \mu \mathrm{Ci}$ of $\left[{ }^{3} \mathrm{H}\right]$-thymidine (ICN Radiochemicals Inc ., Irvine $\mathrm{CA}$, sp. act. $6.7 \mathrm{Ci} / \mathrm{mM}$ ) was added to each well. Cultures were harvested by the MASH II automatic cell harvester (Microbiological Assoc, Rockville, MD), and samples were assayed for radioactivity in a liquid scintillation counter (Beckman, Model LS 1800). Results were expressed as $\bar{X} \pm \mathrm{S}$ of count per minute (cpm) of triplicates or quadruplicates.

\section{Assay of suppressive effect of Tk}

For lymphoproliferation to soluble antigen, $8 \times 10^{4} \mathrm{PBMCs}$ were cocultured with $0.02 \mathrm{Lf}$ TT in $0.2 \mathrm{ml}$ culture medium for $6 \mathrm{~d}$. For lymphoproliferation to mitogen, $8 \times 10^{4} \mathrm{PBMCs}$ were cocultured with 0.1 or $1 \mu \mathrm{g}$ PHA in $0.2 \mathrm{ml}$ culture medium for $3 \mathrm{~d}$. For lymphoproliferation to alloantigen (MLC), $8 \times 10^{4} \mathrm{PBMCs}$ (responding cells) plus $8 \times 10^{4} \mathrm{PBMCs}$ irradiated with 3,000 rads (stimulating cells) were cocultured in $0.2 \mathrm{ml}$ culture medium for $6 \mathrm{~d}$. Pooled PBMCs of four or more unrelated donors were used as the stimulating cells.

Either $2 \mu \mathrm{l} \mathrm{Tk}$ was added at the test concentration to cell cultures, or the cells were pulse-treated by incubating $2 \mathrm{ml} \mathrm{PBMCs}\left(2 \times 10^{6} / \mathrm{ml}\right)$ in RPMI-1640 medium in a $15 \mathrm{ml}$ centrifuge tube with $0.2 \mathrm{ml}$ properly diluted $\mathrm{Tk}$ (usually 1:20, giving a final concentration of $5 \mu \mathrm{g} / \mathrm{ml}$ ) at $37^{\circ} \mathrm{C}$ for $2 \mathrm{~h}$. Cells were collected, washed 3 times, and cultured with TT, PHA, or allogeneic cells as described above. Control cells were treated with saline. The net inhibitory effect of Tk on the test systems was expressed as percent of suppression of relative response (RR).

$$
\begin{aligned}
& \mathrm{RR}=\frac{\mathrm{cpm} \text { of culture with } \mathrm{Tk} \text { treatment }}{\mathrm{cpm} \text { of control culture }} \times 100 \\
& \% \text { suppression }=100-\mathrm{RR}
\end{aligned}
$$

\section{Cell fractionation}

PBMCs $\left(10^{7} / \mathrm{ml}\right.$ in $7 \%$ PHS-RPMI) were mixed with an equal volume of $2 \%$ AET-SRBC (2-aminoethylisothioronium bromide-treated sheep red blood cells), centrifuged, and incubated overnight at $4{ }^{\circ} \mathrm{C}$ to separate the $\mathrm{T}$ cell-enriched (rosetted) fraction from non $\mathrm{T}$ (non-rosetted) cells [16]. As determined by immunofluorescent assay with McAb OKT3 (Ortho Diagnostic System Inc, Raritan, NJ), $91.0-93.6 \%$ of the rosetted samples and $0-5.7 \%$ of the non-rosetted samples were the $\mathrm{CD}^{+}$cells. 
Trichosanthin-induced human immune suppression

\section{Depletion of CD8-bearing cells by complement-dependent cytolysis}

A modification of the method of Pack and Rich was used[17]: $1 \times 10^{7}$ pelleted PBMCs were suspended in $2.5 \mathrm{ml}$ of OKT8 McAb (Ortho Diagnostic System Inc) diluted to 1:250 and incubated at $4{ }^{\circ} \mathrm{C}$ for $30 \mathrm{~min}$. After removing the McAb solution by centrifugation, $1 \mathrm{ml}$ of previously titered and properly diluted complement from rabbits aged 3-4 wk (Pel-Frees, Brown Deer, WI) was added to the cell pellets and the resuspended cells were incubated in $37{ }^{\circ} \mathrm{C}$ water bath for another $30 \mathrm{~min}$. Cells were then washed twice, resuspended in $7 \%$ PHS-RPMI 1640 and adjusted to the desired concentration based on viable cell counting. The $\mathrm{CD}^{+}$cells contaminated in the CD8-depleted samples were $2-3 \%$ as determined by indirect immunofluorescent assay.

\section{Assay with supernatant}

PBMCs were pulse-treated with $\mathrm{Tk}(5 \mu \mathrm{g} / \mathrm{ml})$ or saline, as described above. After washing, $2 \times 10^{6}$ cells were cultured in $2 \mathrm{ml}$ of $7 \%$ PHS-RPMI 1640 for $6 \mathrm{~d}$ without any stimuli added. Supernatants were collected, passed through $0.45 \mu \mathrm{m}$ millipore filter, and mixed with fresh medium at various ratios for MLC.

\section{Detecting Tk in supernatants}

The amount of Tk in the supernatants from the cultures with Tk-pulsed cells were determined by ELISA using the Vectastain ABC kits (Vector Laboratories, Burlingame, CA). Each well of a microtiter plate was coated by incubation overnight at $4{ }^{\circ} \mathrm{C}$ with anti $\mathrm{Tk}$ polyclonal antibody which was raised by immunizing the rabbit with Tk. After washing with $0.005 \%$ Tween 20 in PBS (PBS-Tween), the wells were blocked by incubation with PBS-Tween containing $10 \%$ fetal calf serum (Shen-Niu Inc, Shanghai) for $1 \mathrm{hr}$. The cultured supernatants or the solutions with graded Tk doses as control were added into wells and the plates were kept at $37^{\circ} \mathrm{C}$ for $1 \mathrm{~h}$. Unbound Tk was removed by washing with PBS-Tween. Then added was 1:200 diluted mouse anti Tk McAb (titer 1:10,000), which was kindly given by Dr Yeh [14]. The biotinylated horse anti-mouse lgG and horseradish peroxidase substrate OPD were further used to develop enzyme reactivity as described in the procedure offered by the Vectastain ABC kit. Absorbance was read at $490 \mathrm{~nm}$ by a microplated autoreader (Bio-Tek).

\section{RESULTS}

\section{Inhibition of lymphoproliferation by $T k$}

The dose-response curves of Tk-induced inhibition were similar for the 3 test systems in which different antigens or lectin were introduced (Fig 1). The doses causing approximately $50 \%$ inhibition were $0.05 \mu \mathrm{g} / \mathrm{ml}$ for $\mathrm{TT}$ and alloantigen stimulation, and $0.5 \mu \mathrm{g} / \mathrm{ml}$ for PHA, respectively. The remainder of the experiments included here is limited to the antigen specific systems.

The ability of $\mathrm{Tk}$ to decrease lymphoproliferation was not due to cell killing, because, even after coculture for $6 \mathrm{~d}$ with Tk, the mean viability of PBMCs for 3 healthy volunteers determined by trypan blue exclusion test, was $98.7 \% \pm 0.3$ vs $98.9 \%$ 土 0.3 for the control when the $\mathrm{Tk}$ doses were limited up to $5 \mu \mathrm{g} / \mathrm{ml}$ (Tab 1). Furthermore, at a $\mathrm{Tk}$ concentration of $0.5 \mu \mathrm{g} / \mathrm{ml}$, recovery of viable cells from $6 \mathrm{~d}$ coculture was almost the same as the control $(72.4 \%$ 土 10.2 and $70.9 \%$ 士 3.2 , respectively). However, some cell loss was observed (recovery 60.2\% 士 5.1) when PBMCs were treated with the highest concentration of Tk $(5 \mu \mathrm{g} / \mathrm{ml})$ for $6 \mathrm{~d}$.

In the TT test system, pulse-treatment of cells with Tk induced a suppression of 
the response in a dose-dependent manner (Tab 2) similar to that in the coculture experiments mentioned above. This suggested that the low responsiveness induced by Tk-pulsed cells was not a consequence of dysfunction of antigen or soluble factors such as cytokines responsible for the TT -induced lymphoproliferation, since there was no Tk in the medium to damage or interfere with the soluble components.
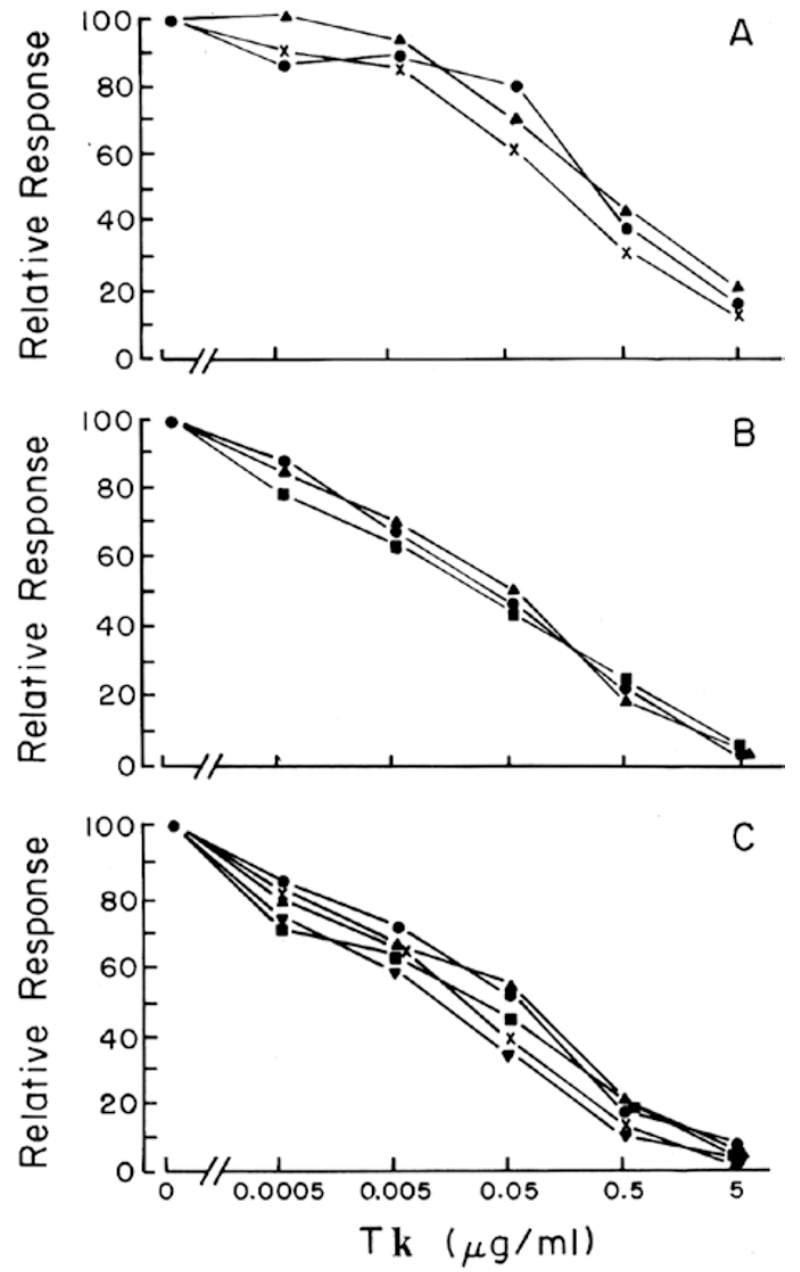

Fig 1. Dose-dependent curve of Tk-induced inhibition of lymphoproliferation in 3 test systems A. Relative responses (\%) of 3 subjects to PHA;

B. Relative responses (\%) of 3 subjects to TT;

C. Relative responses $(\%)$ of 5 subjects in mixed lymphocyte culture test. 
Trichosanthin-induced human immune suppression

Tab 1. Cell viability and recovery after culture with $\mathrm{Tk}^{*}$

\begin{tabular}{|c|c|c|c|c|c|}
\hline & \multirow{2}{*}{$\begin{array}{c}\mathrm{Tk} \\
(\mu \mathrm{g} / \mathrm{ml})\end{array}$} & \multicolumn{4}{|c|}{ Days in culture with $\mathrm{Tk}$} \\
\hline & & 0 & 1 & 3 & 6 \\
\hline \multirow[t]{3}{*}{ Viability } & 0 & $99.2 \pm 0.4$ & $99.2 \pm 0.7$ & $97.5 \pm 1.7$ & $98.8 \pm 0.7$ \\
\hline & 0.5 & - & $99.8 \pm 0.4$ & $98.6 \pm 0.8$ & $99.1 \pm 0.6$ \\
\hline & 5 & - & $99.5 \pm 0.9$ & $97.4 \pm 1.7$ & $99.7 \pm 0.3$ \\
\hline \multirow[t]{3}{*}{ Recovery } & 0 & 100 & $95.9 \pm 4.9$ & $81.1 \pm 6.1$ & $70.9 \pm 3.2$ \\
\hline & 0.5 & - & $91.1 \pm 12.8$ & $85.6 \pm 7.6$ & $72.4 \pm 10.2$ \\
\hline & 5 & - & $86.6 \pm 6.2$ & $70.1 \pm 7.0$ & $60.2 \pm 5.1$ \\
\hline
\end{tabular}

* Viability was determined by trypan blue exclusion. Recovery is the percentage of preculture cell number recovered from Tk culture.

Data are expressed as $\bar{X} \pm \mathrm{S}$ of results of triplicate cultures of 3 subjects.

Tab 2. Suppression of response to TT by Tk-pulsed PBMCs*

\begin{tabular}{clcr}
\hline $\operatorname{Exp}$ & $\begin{array}{c}\mathrm{Tk} \\
(\mu \mathrm{g} / \mathrm{ml})\end{array}$ & $\mathrm{cpm}$ & $\mathrm{RR}(\%)$ \\
\hline \multirow{2}{*}{1} & 0 & $47,016 \pm 6,699$ & 100.0 \\
& 0.05 & $26,491 \pm 4,651$ & 56.3 \\
& 0.5 & $19,982 \pm 3,421$ & 42.6 \\
& 5 & $14,032 \pm 1,640$ & 29.2 \\
\hline \multirow{2}{*}{2} & 0 & $42,251 \pm 8,814$ & 100.0 \\
& 0.05 & $23,281 \pm 3,928$ & 55.1 \\
& 0.5 & $20,114 \pm 2,709$ & 47.6 \\
& 5 & $17,669 \pm 3,398$ & 34.7 \\
\hline
\end{tabular}

* PBMCs were incubated with Tk or saline (when $\mathrm{Tk}=0$, as control) for $2 \mathrm{~h}$ at $37^{\circ} \mathrm{C}$ (pulse-treating), washed 3 times, and coculture with $0.1 \mathrm{Lf} / \mathrm{ml}$ TT for $6 \mathrm{~d}$.

Fig 2. Comparison of differences in exposure time to Tk on levels of suppression of alloreactivity.

The results are expressed as $\bar{X} \pm \mathrm{S}^{3}$
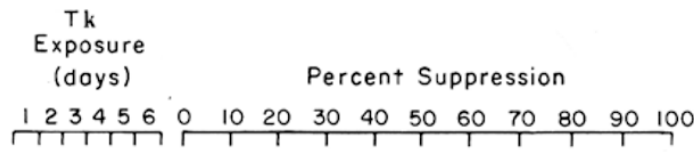

ว
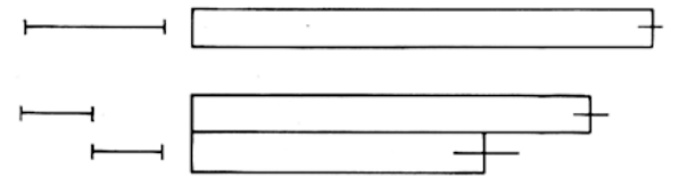

।

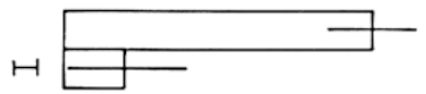

Alloreactivity was suppressed by $94.2 \%$ with $5 \mu \mathrm{g} / \mathrm{ml}$ Tk in the $6 \mathrm{~d}$ MLC (Fig 2 ). Exposure of the cells with the same concentration for $24 \mathrm{~h}$ on the 1 st $\mathrm{d}$ culture 
resulted in a suppression as high as $63.2 \%$. However, if the treatment was performed on the last day of culture for $24 \mathrm{~h}$, the degree of suppression was only $13.4 \%$ (Fig 2 ). This indicated that Tk suppression is most effective at the early stage of alloreaction.

When the Tk-pulsed PBMCs were incubated for $6 \mathrm{~d}$ with neither antigenic nor mitogenic stimulant, the supernatants collected were still able to suppress the MLC in a dose-dependent manner as shown in 2 separate experiments (Tab 3).

Tab 3. Suppression of MLR by supernatants of Tk-pulsed PBMCs*

\begin{tabular}{|c|c|c|c|c|c|c|}
\hline \multirow[t]{2}{*}{ Exp } & \multirow{2}{*}{$\begin{array}{l}\text { med:sup* } \\
\text { (v:v) }\end{array}$} & \multicolumn{2}{|l|}{ Control } & \multicolumn{2}{|l|}{$\mathrm{Tk}$} & \multirow{2}{*}{$\begin{array}{c}\% \\
\text { Suppression \# }\end{array}$} \\
\hline & & $\mathrm{cpm}$ & RR (c) & $\mathrm{cpm}$ & $\mathrm{RR}(\mathrm{t})$ & \\
\hline \multirow{3}{*}{1} & $1: 0$ & $15,509 \pm$ & 100.0 & $17,519 \pm 3,618$ & 100.0 & 0 \\
\hline & $1: 0.33$ & $14,849 \pm$ & 95.7 & $12,525 \pm 2,552$ & 71.4 & 25.4 \\
\hline & $1: 1$ & $11,229 \pm 1,788$ & 72.4 & $6,622 \pm 2,572$ & 37.8 & 47.8 \\
\hline \multirow{3}{*}{2} & $1: 0$ & $23,228 \pm 5,904$ & 100.0 & $25,699 \pm 3,194$ & 100.0 & 0 \\
\hline & $1: 0.33$ & $22,290 \pm 2,853$ & 96.1 & $21,712 \pm 7,794$ & 84.6 & 12.0 \\
\hline & $1: 1$ & $19,090 \pm 2,324$ & 82.3 & $12,709 \pm 3,585$ & 49.5 & 39.9 \\
\hline
\end{tabular}

* med: fresh culture medium; sup: culture supernatants with pulse-treated PBMCs

$\# \%$ Suppression $=\left[1-\frac{R R(t)}{R R(c)}\right] \times 100$

$\mathrm{RR}(\mathrm{c})=$ relative response $(\%)$ for pulsing with saline control

$\mathrm{RR}(\mathrm{t})=$ relative response $(\%)$ for pulsing with $\mathrm{Tk}(5 \mu \mathrm{g} / \mathrm{ml})$

\section{Suppression of responsiveness to TT by transferred, Tk-pulsed cells}

Saline-pulsed PBMCs, used as control, were irradiated and distributed to the cultures with fresh cells and TT. Because of improvement of cell contact condition resulted from a greater cell density, the $\left[{ }^{3} \mathrm{H}\right]$-thymidine incoporation increased in proportion to the number of cells added, as shown in the control groups in 2 independent experiments in Tab 4. In contrast, when the same number of irradiated cells pulsed with Tk were used as modulator, the TT-induced lymphoproliferation was decreased proportionately. This suggested that the immune suppression could also be induced by cells previously sensitized to $\mathrm{Tk}$, inasmuch as there was no $\mathrm{Tk}$ contained in the culture to which the cells were transferred.

Since even a trace of Tk can induce suppression when cocultrued with cells, it was neccessary to make sure that there were no more Tk shedding from the surface of Tk-pulsed cells during cultivation. Special assay was performed to determine the amount of free $\mathrm{Tk}$ in the supernatants or the cultured medium in which the Tk-pulsed cells had been bathed for either $16 \mathrm{~h}$ or $6 \mathrm{~d}$ with the same conditions as in the experiments presented in Tab 3. The choice of incubation for $16 \mathrm{~h}$ was to exclude the possible activity of free Tk appeared at an early stage. Comparing with the standard dose curve of reference Tk solution, no detectable amount of Tk was assayed by ELISA with anti-Tk monoclonal antibody for the 2 experimental groups even the Tk doses used for pulse-treatment were as high as 5 or $50 \mu \mathrm{g} / \mathrm{ml}$ (Fig 3). 
Trichosanthin-induced human immune suppression

Tab 4. Suppression of TT response by transferred Tk-pulsed PBMCs

\begin{tabular}{|c|c|c|c|c|c|c|}
\hline \multirow{2}{*}{ Exp } & \multirow{2}{*}{$\mathrm{p}: \mathrm{p}^{\prime *}$} & \multicolumn{2}{|l|}{ Control } & \multicolumn{2}{|l|}{ Tk } & \multirow{2}{*}{$\begin{array}{c}\% \\
\text { Suppression \# }\end{array}$} \\
\hline & & $\mathrm{cpm}$ & $\mathrm{RR}(\mathrm{c})$ & $\mathrm{cpm}$ & $\mathrm{RR}(\mathrm{t})$ & \\
\hline \multirow{4}{*}{1} & $1: 0$ & $11,013 \pm 2,236$ & 100.0 & $16,779 \pm 2,177$ & 100.0 & 0.0 \\
\hline & $1: 0.125$ & $14.007 \pm 1,575$ & 127.2 & $15,297 \pm 5.812$ & 91.2 & 28.3 \\
\hline & $1: 0.5$ & $16,352 \pm 1,487$ & 148.5 & $14,490 \pm 1,380$ & 86.4 & 41.8 \\
\hline & $1: 1$ & $22,332 \pm 3,439$ & 202.8 & $13,326 \pm 2,596$ & 79.4 & 60.8 \\
\hline \multirow{4}{*}{2} & $1: 0$ & $20,654 \pm 3,614$ & 100.0 & $27,421 \pm 2,095$ & 100.0 & 0.0 \\
\hline & $1: 0.125$ & $22,713 \pm 1,436$ & 109.0 & $25,519 \pm 5,127$ & 93.1 & 15.3 \\
\hline & $1: 0.5$ & $28,267 \pm 1,386$ & 136.9 & $24,430 \pm 5,096$ & 89.1 & 34.9 \\
\hline & $1: 1$ & $34,743 \pm 2,891$ & 168.2 & $21,733 \pm 1,502$ & 79.4 & 60.8 \\
\hline
\end{tabular}

* Ratio of fresh PBMC (P) to autologous, saline-or Tk-pulsed PBMC (P')

$\mathrm{P}^{\prime}$ was irradiated to prevent from proliferation.

\# For calculation of $\%$ suppression see the footnote of Tab 3.

Fig 3. Detection of Tk in culture medium by ELISA

- - The standard curve with graded Tk doses in fresh culture medium as control;

$\triangle-\triangle$ Tk in the medium incubated with Tk-pulsed PBMCs for 6 days. Tk concentration stands for the doses for pulse-treatment;

$X-X$ Tk in the medium incubated with Tk-pulsed PBMCs for $16 \mathrm{hrs}$. Tk concentration stands for the doses for pulse-treatment.

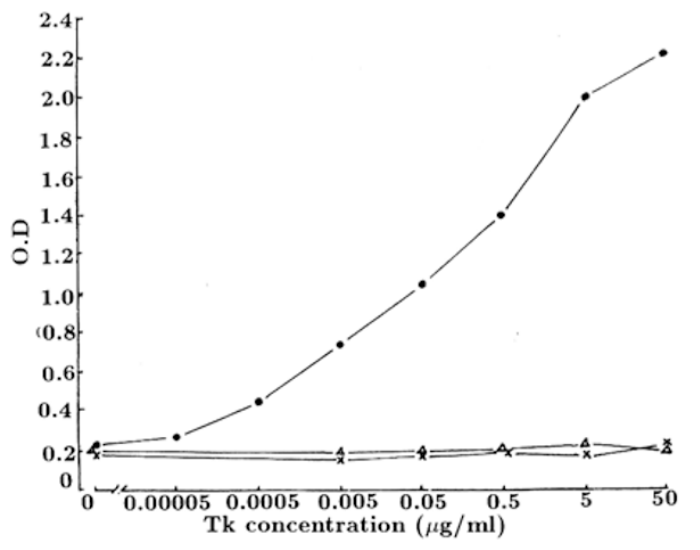

\section{Dependence of Tk-induced suppression on CD8-bearing cells}

E-rosetted T lymphocytes were fractionated into CD4 and CD8 subsets by treating T cells with McAbs OKT8 and OKT4 plus complement, respectively. A reconstitution experiment was carried out using the TT test system to assess the function of CD8 cells in Tk-induced suppression. When total $\mathrm{T}$ cells (Tt) plus antigen presenting cells (APC) at a ratio of 1:0.25 were stimulated with antigen TT, the mean cpm was $16,402 \pm 3,654$ for quadruplicates. With the addition of $\mathrm{Tk}$, the mean cpm declined to $5,970 \pm 1,857$, giving a relative response value (RR) only of 36.4 $\%$ as shown in Exp 1 of Tab 5. If $\mathrm{CD}^{+}$cells were depleted, leaving only $\mathrm{CD} 4^{+}$ cells in the responding cell population, the Tk-induced response restored to $66.1 \%$. When $\mathrm{CD}^{+}{ }^{+}$cells were returned to the culture in a ratio of CD4: CD8 of 4:1 or 2:1, the responses were reduced again to levels of $21.5 \%$ and $25.9 \%$, respectively. The re-appearance of suppression was not due to the increase of cell density, because the substitution of modulator $\mathrm{CD}^{+}$cells with $\mathrm{Tt}$ in a same amount did not change the 
relative response as compared with the $\mathrm{RR}$ value of the experimental group $\left(\mathrm{CD} 4^{+}\right.$ + APC ) in which no modulator cells were added. Similar reaction pattern was observed in the Exp 2 of Tab 5. This suggested that $\mathrm{CD}^{+}$suppressor $\mathrm{T}$ cells were responsible, at least in part, for the Tk-induced suppression.

Tab 5. Mediation of Tk-induced suppression by CD8-bearing cells in the lymphoproliferation to TT

\begin{tabular}{|c|c|c|c|c|c|c|}
\hline \multirow{2}{*}{ Exp } & \multirow{2}{*}{$\mathrm{R}^{*}$} & \multirow{2}{*}{ APC } & \multirow{2}{*}{ M } & \multicolumn{2}{|c|}{$\mathrm{Tk}(\mu \mathrm{g} / \mathrm{ml})$} & \multirow{2}{*}{$\mathrm{RR}$} \\
\hline & & & & 0 & $0.05-0.5$ & \\
\hline \multirow[t]{6}{*}{1} & $\mathrm{Tt} \#$ & $1: 0.25$ & & $16,402 \pm 3,654$ & $5,970 \pm 1,857$ & 36.4 \\
\hline & $\mathrm{CD} 4$ & $1: 0.25$ & & $14,896 \pm 3,993$ & $9,844 \pm 1,867$ & 66.1 \\
\hline & CD4 & $1: 0.25$ & $\mathrm{Tt}(1: 0.25)$ & $20,734 \pm 1,934$ & $13,912 \pm 2,834$ & 67.1 \\
\hline & CD 4 & $1: 0.25$ & CD8 (1:0.25) & $31,566 \pm 3,305$ & $6,772 \pm 1,438$ & 21.5 \\
\hline & CD4 & $1: 0.25$ & $\mathrm{Tt}(1: 0.5)$ & $26,390 \pm 6,202$ & $18,777 \pm 4,113$ & 71.2 \\
\hline & CD 4 & $1: 0.25$ & CD8 (1:0.5) & $35,434 \pm 4,376$ & $9,162 \pm 2,736$ & 25.9 \\
\hline \multirow[t]{3}{*}{2} & CD4 & $1: 0.25$ & & $13,019 \pm 684$ & $7,364 \pm 1,637$ & 56.6 \\
\hline & CD4 & $1: 0.25$ & Tt (1:0.5) & $32,204 \pm 3,964$ & $17,888 \pm 1,073$ & 55.6 \\
\hline & CD4 & $1: 0.25$ & CD8 (1:0.5) & $22,135 \pm 3,597$ & $8,652 \pm 2,524$ & 39.1 \\
\hline
\end{tabular}

* R: responder cells; M: modulator cells irradiated with 1000 rads. APC: $\mathrm{B}$ cells and monocytes irradiated with 3000 rads.

\# Tt: purified total T cells; CD4: CD8-depleted Tt; CD8: CD4depleted Tt.

Fig 4. Proliferation of CD4 and CD8 T cells to tetanus toxoid (TT)

Responding cells $(\mathrm{R})$ include: total $\mathrm{T}$ cells (Tt) with $(\times)$ or without ( $)$ TT; CD4positive T cells with TT ( $\mathbf{\Delta})$; CD8-positive T cells with TT

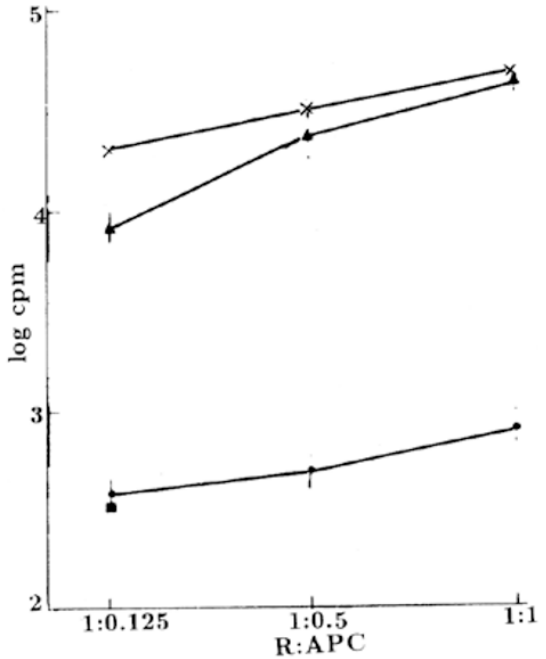

To assess the capability of $\mathrm{CD}^{+}$cells to proliferate to soluble antigen, purified CD4 and CD8 cells were stimulated separately with TT in the presence of APC (Fig 4). Results showed that at a ratio of responding cells ( CD4 or CD8) to APC as $1: 0.5$, CD 8 cells did not keep on proliferation as in the case of negative control. In contrast, CD4 cells responded to antigen TT quite well with more than $20000 \mathrm{cpm}$, similar to the positive control culture in which unfractionated $\mathrm{Tt}$ were stimulated 
Trichosanthin-induced human immune suppression

with TT. It is obvious that the failure of TT to induce proliferation of CD8 cells is not due to shortage of antigen presenting cells because it was helpless even if the APC amount was doubled.

\section{DISCUSSION}

The toxic property of trichosanthin (Tk) has been claimed to be the primary agent by which this drug induces abortion [2,4] and destroys malignant cells[18]. According to its primary structure and action on ribosome[5,19], Tk is believed to exert its cytotoxic effect as a single chain RIP by inhibiting protein synthesis, which was determined in a cell-free system[20,21]. It does not mean, of course, that the doses of $\mathrm{Tk}$ showing cytotoxicity in the cell-free system exhibit an equal effect on intact living cells.

With lower doses of Tk in our experiments, cell lysis seemed not to be a mechanism underlying the immune hyporesponsiveness. For pulse-treatment with $\mathrm{Tk}$ at $5 \mu \mathrm{g} / \mathrm{ml}$, for example, the suppression could reach $65.3-70.1 \%$ with no noticeable cytolysis when Tk-exposure was limited to $2 \mathrm{~h}$ (Tab 2). And for a $6 \mathrm{~d}$ coculture treatment with $\mathrm{Tk}$, no more cytolytic effect was detectable both in terms of cell viability and cell recovery for $0.5 \mu \mathrm{g} / \mathrm{ml}$ of $\mathrm{Tk}$ ( Tab 1). But the same concentration of the drug caused an approximate $60 \%$ of inhibition for PHA-induced lymphoproliferation and $80 \%$ of inhibition for TT-and alloantigen-induced responses (Fig $1)$.

The term 'cytotoxicity', in its broader sense, includes both cytolysis and cytostasis. There are at least 2 non-cytolytic mechanisms in connection with the Tk-induced hyporesponsiveness: cytostasis and immune suppression. The differential effects of the pulse-treatment of cells with Tk on the first and the last day of $6 \mathrm{~d}$ MLC (Fig 2) favored the argument that immune suppression could be one of the main mechanisms leading to the low uptake of $\left[{ }^{3} \mathrm{H}\right]$-thymidine. Moreover, the fact that the Tk-pulsed cells were able to transfer suppression to a Tk-free culture (Tab 4) in a dose-dependent manner could be explained neither by cytolytic nor by cytostatic-like effect of the drug.

The reconstitution experiment with cell subsets, which followed experiments in Tab 4, indicated a special role played by $\mathrm{CD}^{+}$cells (Tab 5 ). Since CD8 cells were even unable to proliferate to stimulate of the TT antigen in the absence of activated $\mathrm{CD}^{+}$cells (Fig 4), it seemed hardly intelligible to attribute the involvement of CD ${ }^{+}$ cells in the Tk-induced immune suppression to a higher sentitivity to cytostasis. It is usually the proliferating cells on which the cytostasis can show its effect.

Although CD8 cells were involved in the immune suppression as shown above, they could only be accounted for a part of the Tk-induced hyporeactivity. It is reasonable to propose that besides CD8 cells other factors could also be active in the emergence of low-responsiveness, which may or may not be an immunological event. It is possible that cytostasis might be involved in such CD8-independent 
pathway especially when higher doses of Tk are introduced.

A dual property of the Tk preparation at a low dose range was thus detectable: the CD8 cell-mediated immune suppression and the possible cytostasis mediated by CD8-independent pathway, both of which led to immune low-responsiveness. Interestingly, a similar dual property, ie, the non-toxic inhibition of HIV replication and the cytostasis-like activity of disturbing the cell metabolism, could also be observed in all Tk preparations so far developed for AIDS treatment. McGrath et al, for example, reported up to $75 \%$ inhibition of HIV replication in lymphocytes and macrophages after $4 \mathrm{~d}$ exposure in vitro to Tk (GLQ223) at a dose of only 16-63 $\mathrm{ng} / \mathrm{ml}$ with no more than $10 \%$ decrease of protein or DNA synthesis in both HIV infected and uninfected cells (8). The discrepancy between the anti HIV effect and the metabolic inhibition property of $\mathrm{Tk}$ was further verified by another isolated $\mathrm{Tk}$ preparation TAP 29, which showed a potent suppressive activity to HIV replication but was quite free from cytostasis-like effect on DNA and protein synthesis[10]. These data strongly suggested that, instead of RIP-related cytotoxic property, some differential mechanisms accounting for the effect against HIV, were shared by all Tk preparations. The immunosuppressive activity of Tk demonstrated in this communication might be related to the underlying mechanism.

Wang et al observed that prostaglandin concentration in amniotic fluid was promptly increased during abortion induced by $\mathrm{Tk}[22]$, and $\mathrm{Zhu}$ et al reported that Tk induced abortion could be delayed or inhibited when aspirin or amidopirin was fed to gestating mice[23]. These observations suggested there existed an association of endogenous prostaglandin with uterine contractions in Tk-induced abortion. The increased amount of prostaglandin was thought to be due to degeneration, necrosis and destruction of the trophoblastic tissues[2]. However, prostaglandin can also be generated by monocytes or macrophages following interaction with activated suppressor $\mathrm{T}$ cells, which leads to the suggestion that immune suppression might be also involved in prostaglanding production in Tk-induced abortion.

In summary, results in this paper suggested that there are 2 pathways by which Tk exerts its non-cytolytic inhibitory action, one is mediated by $\mathrm{CD}^{+}$suppressor $\mathrm{T}$ cells and the other is the $\mathrm{CD}^{+}$cell-independent pathway. It is not clear at present whether immunological and/or cytostatic mechanisms are involved in the second pathway.

\section{ACKNOWLEDGEMENTS}

We thank Drs Wilma Bias and Maria Chen of the Johns Hopkins University School of Medicine for their supporting part of the experiments and also valuable discussions. We are also grateful to Dr. M Yeh at Shanghai Institute of Cell Biology, Academia Sinica, for her kindly offering the anti-Tk monoclonal antibodies. 
Trichosanthin-induced human immune suppression

\section{REFERENCES}

[1] Li SZ. Ben Cao Gang Mu(Compendium of Materia Medica), reprinted from the ancient editions (1596-1603). Beijing, People’s Medical Publishing House, 1977:1271-2 (in Chinese).

[2] Jin YC. Clinical study of trichosanthin. In: Chang HW, Yeung HW, Tsao WW \& Koo A. eds. Advances in Chinese Medicinal Materials Research, Singapore, World Scientific Publ. 1985:31926.

[3] Jin SW, Sun XX, Wang SF, et al. Chemistry of trichosanthin. I. Physical and chemical properties of crystalline trichosanthin. Acta Chem Sin, 1981; 42:943-5.

[4] Wang Y, Qian RQ, Gu ZW, et al. Scientific evaluation of Tian Hua Fen (THF)-history, chemistry and application. Pure Appl Chem 1986; 58:789-98.

[5] Zhang XJ, Wang JH. Homology of Trichosanthin and ricin A chain. Nature (London), 1986; 321:477-8.

[6] Wang QC, Ying WB, Xie H, Zhang ZC, Yang ZH \& Ling LQ. Trichosanthin-monoclonal antibody conjugate specifically cytotoxic to human heptoma cells in vitro. Cancer Res 1991; 51:3353-6.

[7] Ge HL, Chou KY, Lu DY. Trichosanthin-CEA MAb conjugate cytotoxic to human colonic carcinoma, Chin J Immunol, 1992; 8:300-4.

[8] McGrath MS, Hwang KM, Galdwell SE, et al. GLQ223: an inhibitor of human immunodeficiency virus replication in acutely and chronically infected cells of lymphocyte and mononuclear phagocyte lineage. Proc Natl Acad Sci USA 1989; 86:2844-8.

[9] Ferrari P, Trabaud MA, Rommain M, et al. Toxicity and activity of purified trichosanthin. AIDS 1991; 5:865-70.

[10] Lee-Huang S, Huang PL, Kunag HF, et al. TAP 29: an anti-human immunodeficiency virus protein from Trichosanthes kirilowii that is nontoxic to intact cells. Proc Natl Acad Sci USA, $1991 ; 88: 6570-4$

[11] Byers VS, Levin AS, Waites LA, et al. A phase I/II study of trichosanthin treatment of HIV disease, AIDS, 1990; 4:1189-96.

[12] Kahn JO, Kaplan LD, Gambertoglio JG, et al: The safety and pharmacokinetics of GLQ223 in subjects with AIDS and AIDS-related complex: A phase I study, AIDS 1990; 4:1197-204.

[13] Chow TP, Feldman RA, Lovett M, Piatak M. Isolation and DNA sequence of a gene encoding a-trichosanthin, a type I ribosome-inactivating protein. J Biol Chem, 1990; 265:8670-4.

[14] Yeh M, Chi YY, Shen RY, Lin GM. The study of in vitro and in vivo responses to trichosanthin in mouse. Acta Biol Exp Sin 1986; 19:81-90.

[15] Leung KN, Yeung HW, Leung SO. The immunomodulatory and antitumor activity of trichosanthinan abortifacient protein isolated from Tian-Hua Fen (Trchosanthes kirilowii). Asia Percific J Allergy Immunol 1986; 4:111-20.

[16] Foung SKH, Loutre S, Engelman EG. Seperation of human T and non-T lymphocyte from peripheral blood. In: Engelman EG, Foung SKH, Larrick J, Raubitacker A, eds, Human Hybridoma and Monoclonal Antibodies. New York. Plenum. 1985:437-40.

[17] Pack JM, Rich RR. Regulatory interactions governing the proliferation of T cell subsets stimulated with pokweed mitogen. J Immunol 1984; 132:1106-12.

[18] Tsao SW, Yan KT, Yeung HW. Selecting killing of choriocarcinoma cells in vitro by trichosanthin, a plant protein purified from root tubers of the Chinese medicinal herb Trichosanthes kirilowii. Toxican 1986; 24:831-40.

[19] Zhang JS, Liu WY. The mechanism of action of trichosanthin on eukaryotic ribosomes-RNA N-glycosidase activity of the cytotoxin. Nuc Aci Res 1992; 20:1271-5.

[20] Wang QC, Zhang ZF, Wang J,Xie H, Yang ZH. Trichosanthin has potent inhibiting activity of protein synthesis in a cell-free system and its antibody-conjugate exhibits cytotoxicity to tumor cells in vitro. Acta Biol Exp Sin 1987; 20:515-9.

[21] Collins EJ, Robertust JD, LoPresti M, et al. Primary amino acid sequence of a-trichosanthin and molecular models for abrin-A-chain and a-trichosanthin. J Biol Chem 1990; 265:8665-9. 
[22] Wang YF, Zhou WD, Liu JX, et al. Prostaglandin E and F2a levels in plasma and amniotic fluid during mid-trimester abortion induced by trichosanthin. Prostaglandins 1981; 22:289-94.

[23] Zhu YP, Cai SP. Studies on the relationship between endogenous synthesis of prostaglandins and abortion induced by trichosanthin, Acta Zool Sin 1976; 22:180-6.

Received 6-4-1993. Revised 10-11-1993. Accepted 2-12-1993 